\title{
Três Lições do Professor Wisner
}

Leda Leal Ferreira ${ }^{2}$

\footnotetext{
Tradução da apresentação realizada no Colloque Alain Wisner et les tâches du notre temps 19 e 10 de março de 2001, em Aix-en-Provence, França), publicada em francês por Duraffourg \& Vuillon (2004).

${ }^{2}$ Doutora em Ergonomia pela Universidade Paris XIII, pesquisadora da Fundacentro.
}

Estou muito feliz por poder participar desta homenagem ao Professor Wisner e agradeço aos organizadores do colóquio o seu convite.

Desde que tomei conhecimento do tema do encontro - Alain Wisner e as tarefas do nosso tempo - fiquei me perguntando qual poderia ser minha contribuição. Pedi auxílio a François Daniellou, mas quero adiantar que não segui sua sugestão. Ele me propunha falar do papel do professor no desenvolvimento da Ergonomia nos chamados países em desenvolvimento industrial, os PVDI, provavelmente com o intuito de homenagear o grande trabalho que há décadas o professor faz fora da França, em vários países do mundo, em particular no meu, o Brasil. Se a idéia de realçar o papel de Wisner no desenvolvimento da Ergonomia além França é altamente louvável e meritória, declaro-me incompetente para realizá-la.

Primeiro porque não acredito que haja uma unidade chamada PVDI. Brasil e Índia são países profundamente diferentes, tão diferentes quanto México e China, por exemplo, embora todos sejam chamados de PVDI. O próprio professor compartilhava esta idéia quando escreveu (1), em 1985, que "a ambição de tratar de ergonomia em PVDI não é razoável", dando como um dos motivos a ambigüidade do conceito e um argumento irrefutável: os PVDI se referem a três quartos dos países do mundo, o que representa, em números atuais, cerca de 4,5 bilhões de seres humanos. Acredito até que seria bem mais fácil falar da Ergonomia nos países industrializados, mas acho que talvez ninguém se habilitasse a tanto pelas dificuldades de encontrar um denominador comum entre as escolas japonesas, norte-americanas, italianas e alemãs, apenas para citar alguns países que me vêm à memória.

Segundo porque também não acredito que haja uma unidade chamada Ergonomia. Desde sua criação, a Ergonomia sempre sofreu de uma crise de identidade. Conta Kuorinka (2) que os participantes dos primeiros encontros para a criação da International Ergonomics Association, logo após a Segunda Guerra Mundial e no seio dos programas de recuperação da Europa do Plano Marshall, em particular dos da Agence Européenne de Productivité, tiveram grandes discussões para se acertarem sobre a denominação da nova disciplina, até optarem pela neutralidade da palavra grega "ergonomia", já utilizada pelos ingleses. Para a nova associação foi proposto, por exemplo, o nome de International Association for Biological Sciences of Human Work e os alemães e os franceses pareciam preferir biotecnologia à ergonomia. Essa discussão em relação ao nome da disciplina permanece: a maior associação de ergonomistas do mundo, a norte-americana, chama-se até hoje Human Factors e só a partir dos anos de 1990 acrescentou (e não trocou) Ergonomics ao seu nome, tornando-se a Human Factors and 
Ergonomics Society. Já a tradicional Ergonomics Society inglesa anuncia que pretende acrescentar Human Factors à sua denominação. Eaté hoje as denominações Engineering Psychology ou Human Engineering convivem e se confundem com a Ergonomia nos Estados Unidos. Sem falar na Ergologia japonesa.

Não é apenas uma questão de nomenclatura que está em jogo, mas de diferentes concepções em luta, aflorada pela questão da nomenclatura. Prova disso são as várias definições propostas para a disciplina ao longo da sua curta existência. Algumas delas são tão longas que mais parecem ementas de cursos.

Acredito que uma de nossas tarefas atuais seja a de contar melhor a história desta disciplina, procurando esclarecer por que ela surgiu, quem foram seus precursores, onde trabalharam, 0 que fizeram, quais foram seu objetivos. Esta parece ser uma preocupação que se difunde, pois começam a aparecer referências históricas a momentos da vida de associações nacionais e da IEA. Que sejam bem-vindas! Talvez assim possamos encontrar explicações para os problemas que assolam a Ergonomia atual, que a meu ver sofre de um inchaço desproporcional, com o risco de se transformar em uma bolha vazia, e encontrar algumas perspectivas de mudança.

Assim, abandonei a sugestão de meu amigo François e comecei a remexer minha memória. Sempre estive consciente do papel de Wisner na minha história, pessoal e profissional. Quando ele me acolheu no então Laboratoire de Physiologie du Travail et d'Ergonomiet du CNAM da rue Gay-Lussac, em 1977, ofereceu-me não só uma profissão como uma grande amizade, o que jamais se esquece. Mas nunca tinha feito o exercício mental de procurar sistematizar as suas influências e as lições que dele aprendi.

O que trago como contribuição é a síntese dessa reflexão na forma de lições que aprendi com o professor. Embora pessoal, esforcei-me para dela tirar elementos mais gerais para submetê-los à discussão. É que acho que as "três lições" do professor Wisner continuam mais vivas do que nunca e podem nos ajudar, como propõe este colóquio, nas nossas tarefas do presente. E isso não se limita ao campo da Ergonomia stricto sensu, nem a um tipo de país. As lições do professor ultrapassam a disciplina e alcançam um campo muito maior, o do trabalho humano. No Brasil, médicos e paramédicos, Engenheiros, psicólogos e antropólogos conhecem e se referenciam nas obras sobre Ergonomia do professor e também sobre a sua Antropotecnologia. E aqui na França é um Laboratório de Ergologia que nos acolhe para este evento.

\section{Colocar o trabalho no centro das preocupações}

Tive a sorte de estar no Laboratoire d'Ergonomie do CNAM em uma época de apogeu (1977-1980). Eu vinha de um país que vivia uma ditadura militar, com sérias restrições a qualquer atividade organizada, principalmente a política e a sindical. Apesar de recém-formada na melhor faculdade de Medicina de meu país, cujo nível técnico e científico nada deixava a desejar em relação às melhores do mundo, a formação que tive em Medicina do Trabalho foi praticamente nula. O trabalho não era, como, aliás, continua não sendo, uma preocupação dos médicos, mesmo os do trabalho (e acho que este diagnóstico não se restringe ao Brasil...). Eu me perguntava como era possível ignorar uma parte tão importante da vida, a que passamos trabalhando, quando fazíamos os nossos diagnósticos e essa curiosidade me fez procurar, fora da faculdade de Medicina, uma possibilidade de conhecer um pouco o mundo industrial. Consegui então realizar um estágio no Serviço de Medicina do Trabalho da maior fábrica de automóveis da América Latina: a Volkswagen do Brasil, em São Bernardo do Campo, que tinha, em meados dos anos de 1970, quase 40 mil trabalhadores. Cada um de seus galpões, incrivelmente barulhentos e poluídos, empregava milhares de operários que disciplinadamente fundiam, forjavam, prensavam, usinavam e montavam milhões de carros. Eu me sentia completamente despreparada até para entender o que acontecia ali. Faltavam-me instrumentos 
conceituais para orientar o meu olhar, particularmente para observar e entender no que consistia o trabalho daqueles operários e operárias. A equipe de médicos era tosca e, por melhores que fossem suas intenções, também não entendia do trabalho e tinha sérias limitações de ações. Esse estágio foi decisivo na minha orientação profissional: decidi estudar o trabalho e seus efeitos na vida dos homens. Mas não sabia muito bem como começar.

Assim, foi com a maior satisfação que encontrei em Paris, em um ambiente universitário do primeiro mundo, a questão do trabalho como centro das preocupações, motivo de cursos e de pesquisas. Penei um pouco com a língua, tive que me habituar com os hábitos estranhos dos franceses e com o seu modo peculiar de raciocinar. Mas absorvi como uma esponja as discussões que se faziam em torno de conceitos inteiramente novos, como "situação de trabalho", "trabalho real", "trabalho prescrito", "atividade" e "tarefa". E a obrigação de ir a campo, realizar o famoso trabalho prático, O "TPB", era instigante e desafiadora.

Naquela época, o Laboratório era um centro efervescente e não tenho dúvidas de que o papel de Wisner como seu diretor foi fundamental para criar e manter essa efervescência. Ao colocar o trabalho como tema central, o professor abria e estimulava um mundo de possibilidades, de toda sorte.

Do ponto de vista temático, alguns pesquisadores seguiam vias que poderíamos chamar de "micro", preocupando-se em elaborar métodos e técnicas para estudar determinadas particularidades do comportamento humano em situação do trabalho; várias contribuições de membros do Laboratório, pela sua importância, fazem parte do conhecimento universal sobre o homem em situação de trabalho. Em particular, relembro os estudos sobre os operários e as operárias "OS" (3), desenvolvidos por vários pesquisadores, entre eles Catherine Teiger, Antoine Laville, Jacques Duraffourg e Jeanne Marcellin, e o estudo com as telefonistas, de Dominique Dessors. Suas análises continuam atualíssimas e acho que podem contribuir muito para a nossa compreensão do fenômeno atual das temíveis "Lesões por Esforços Repetitivos", que têm assolado cada vez mais trabalhadores, dos mais diversos ramos profissionais, em todos os países. E foram os estudos pioneiros de Jean Foret sobre o sono de trabalhadores em turnos que me estimularam a fazer a minha tese de doutorado.

Outros optavam por uma visão mais "macro", com a preocupação de incorporar temas mais sociais aos métodos de intervenção. Refiro-me ao trabalho contínuo e persistente de elaboração e desenvolvimento do método da Análise Ergonômica do Trabalho e também aos trabalhos que deram origem ao Cours d'Action, de J. Theaureau e L. Pinsky.

No entanto, apesar dessa diversidade, não tínhamos em absoluto uma visão caótica, e mais uma vez destaco o papel do professor como o grande articulador dos pontos de vista particulares. Lembro-me particularmente dos seminários que organizava: momentos de integração, discussão e esclarecimentos entre diferentes abordagens e temáticas a partir da análise de situações concretas.

Colocar o trabalho como centro também exigia decisões políticas para dar voz a várias classes e grupos sociais. $O$ trabalho não é um objeto neutro de pesquisa e todos nós sabemos como são diferentes as análises do trabalho conforme são feitas pelos dirigentes, os técnicos ou os próprios trabalhadores. A sensibilidade de Wisner proporcionou uma convivência no Laboratório entre dirigentes sindicais de diferentes centrais, profissionais de empresas e técnicos de diferentes especialidades e de diversas correntes políticas. Havia debates acalorados, posições opostas que se manifestavam. Mas isso não era um problema e sim um sinal de vida.

Além disso, o professor não queria se limitar a uma visão francesa do mundo do trabalho: vivendo na França, convivi com colegas argelinos e canadenses. Conheci as inquietações de um professor vietnamita que procurava soluções para amenizar os efeitos do trabalho sob sol em um país recém-saído de décadas de guerra e por ela arrasado e assisti às brilhantes, mas infelizmente últimas, palestras do professor russo Ochanine, discorrendo animadamente sobre suas "imagens operatórias". Esse convívio internacional se intensificou nos anos seguintes e criou vínculos importantes entre pesquisadores de várias partes do mundo. 
Assim, a primeira lição que guardei de Wisner foi a de que é possível e vale a pena colocar o trabalho no centro do debate científico.

Mais do que nunca é preciso lembrar desta lição.

Estamos vivendo uma época em que há um esforço enorme das "intelectualidades" em esvaziar o peso do trabalho no mundo - o falacioso discurso sobre o fim do trabalho acompanhado, na prática, de uma desvalorização do trabalho real, aprisionado em prescrições com pretensões universais: o que é exaltado é o trabalho morto, "procedimentalizado", na esteira do que é preconizado pelas grandes firmas de consultoria internacional e aprovado pelos organismos de normatização, que adquirem cada vez mais força e se tornam cada vez mais pretensiosos e audaciosos.

Nesse sentido, a International Organization for Standardization, mais conhecida como ISO, tem tido um papel negativo com a imposição de suas normas ditas de "qualidade total" (as famosas normas ISO da série 9000) a empresas de todo o mundo. Não estou falando apenas em teoria. A penetração das normas ISO é uma realidade no Brasil, um dos países onde o número de certificações é um dos maiores do mundo. O que tenho visto, a partir de meus estudos, é uma prática duplamente prejudicial: por um lado, é enganosa: os certificados ISO, embora apenas certifiquem "sistemas de gestão" com toda a ambigüidade que isso significa, são vistos e vendidos como sistemas de qualidade total, incluindo a qualidade de produtos e serviços, o que não é verdade. Por outro lado, o processo de certificação é extremamente ansiogênico para os "cadres" e, sobretudo, para os trabalhadores. Multiplicam-se as horas de trabalho para se elaborar os tais "procedimentos operacionais", a papelada, os micro e ultrarápidos "treinamentos" e, sobretudo, os controles. Controles explícitos, como o de responsabilizar os trabalhadores por "não seguir os procedimentos operacionais" em caso de qualquer anormalidade, e os controles mais sutis, autocontroles, que criam um clima de insegurança e desconfiança entre colegas. Muito mais que uma solução, considero os programas ditos de "qualidade total" um problema a ser encarado por nós quando estamos realizando uma Análise Ergonômica do Trabalho, como uma "contrainte" a mais, a aumentar a penosidade do trabalho e a contribuir para sua intensificação. Acho mesmo que a comunidade científica internacional ainda está devendo à sociedade uma análise crítica dos resultados dessas práticas do ponto de vista dos trabalhadores.

É avassalador o poder dessas idéias e dessas práticas "procedimentalizadoras", a tal ponto que em vários congressos de Ergonomia, nacionais e internacionais, tem sido aceito, até com regozijo, um discurso laudatório sobre elas. Aumentam a cada ano as comunicações agrupadas sob o nome de ODAM (Organizational Design and Management) e perde-se, cada vez mais, o limite entre as especificidades das diferentes disciplinas e a precisão das análises.

Ao mesmo tempo, e significativamente, aumenta a distância entre institutos de pesquisa e organizações de trabalhadores. São raríssimas as instituições que oferecem, como fazia o Laboratório de Wisner, espaço e condições para os sindicatos se expressarem. É até possível se sair de um congresso de Ergonomia sem ter ouvido uma única vez a palavra trabalhador, muito menos sindicato. Perdemos muito com isso.

\section{Respeitar a inteligência dos povos}

Nos anos em que conheci Wisner, ele ainda não falava de Antropotecnologia, mas não é surpreendente que seu percurso tenha passado da Ergonomia para a Antropotecnologia.

Em uma entrevista com ele, em São Paulo, em 1998, perguntei-lhe sobre as diferenças entre as duas abordagens. Ele discorreu longamente, mas o que retive pode ser sintetizado assim: enquanto a Ergonomia está baseada nas ciências do homem individual - Fisiologia, Psicologia, Antropometria - a Antropotecnologia se preocupa com as ciências do homem coletivo - Economia, Antropologia, Geografia, História. Isso porque as questões que as duas se colocam são 
diferentes: para a Ergonomia, como adaptar o trabalho ao homem, e para a Antropotecnologia, como adaptar a tecnologia aos povos. Em comum nas duas abordagens, o interesse pelo trabalho e a orientação de se observar como os homens trabalham, compreender o que fazem no seu trabalho para entender as origens de suas dificuldades.

Se Singleton (4) dizia que para entender o homem é preciso conhecer o seu trabalho - "Eu me ocupo de psicologia fundamental, é por isso que vou aos locais de trabalho" - Wisner acrescenta que é necessário ultrapassar as fronteiras nacionais e partir para o mundo.

Dos seus primeiros aos últimos textos, vemos suas preocupações se alargarem e ampliarem em diferentes direções.

No campo das idéias, ele tem acompanhado o espantoso crescimento, nas últimas décadas, das ciências do cérebro e das ciências cognitivas. Em uma de suas palestras em São Paulo, confessou a um público de estudantes ter sido obrigado a reaprender inúmeras vezes a Neurofisiologia, tendo que esquecer várias coisas que eram consideradas paradigmas porque elas estavam erradas. Mas ele também tem seguido o que tem sido feito em Antropologia no mundo em suas vertentes cognitiva, cultural, psicológica.

Suas fichas de leitura, com resumos ou traduções integrais para o francês de textos importantes de autores não franco-fônicos, abriram a possibilidade para muitos de se encontrarem com outros pensamentos e redescobrirem autores importantes - Vygotsky, por exemplo - , mas pouco conhecidos. Concebidas pelo professor como instrumento pessoal de trabalho, decidiu ele publicá-las e torná-las disponíveis em primeiro lugar aos seus alunos, que freqüentavam os Seminaires d'Anthropotechnologie, e em seguida a um público mais amplo. Elas são acompanhadas de interessantíssimas observações pessoais do professor e muitas vezes constituem diálogos calorosos com os autores.

A mesma curiosidade que tem pelas novas idéias, o professor tem pelos diferentes povos e 0 testemunho que posso lhes dar diz respeito ao meu país.

É do conhecimento geral o amor que o professor tem pelo Brasil, para o qual já viajou dezenas de vezes nos últimos trinta anos, mais particularmente desde 1974. Nessas viagens, ele conheceu várias de nossas cidades, da efervescente São Paulo, com seus 10,5 milhões de habitantes, a pequenas cidades do Sul e do Nordeste e muitos de seus habitantes. Certamente conhece mais de nosso país do que muitos brasileiros. Jamais, porém, arvorou-se o direito de nos ditar regras. Ao contrário, confessava a sua ignorância à medida que ampliava o conhecimento que tinha de nós. Nunca foi daqueles que chegam, pontificam e vão embora, como acontece com a maioria dos estrangeiros que nos visitam. Sempre trabalhou muito e incansavelmente com seus alunos - foram mais de trinta os brasileiros que se diplomaram no CNAM - e com os alunos de seus alunos brasileiros, e por isso criou uma Escola de Ergonomia no Brasil, reconhecida por todos, mesmo pelos que não compartilham de suas idéias. Há núcleos dessa Ergonomia nas principais universidades públicas brasileiras: na Universidade de São Paulo (USP), com Laerte Sznelwar; na Universidade Federal do Rio de Janeiro (UFRJ), com Mário Vidal; na Universidade de Brasília (UnB), com Júlia Abrahão; na Universidade Federal de Minas Gerais (UFMG), com Francisco Lima e Ada Assunção; e na Universidade Federal de Santa Catarina (UFSC), com Neri dos Santos.

Esse respeito à inteligência dos povos é a segunda grande lição do professor Wisner.

Também ela anda meio esquecida, muito pela pressa dos atuais, que torna tudo superficial. É preciso tempo para se dedicar às pessoas e às suas idéias, para ouvi-las e trabalhar junto com elas, desenvolvendo as suas potencialidades e respeitando suas inteligências. Ou, nas palavras do talvez maior escritor da língua portuguesa, Antonio Vieira, referindo-se às gentes brasileiras nos idos do século XVII, "para se aproveitar e lograr o trabalho, há de ser com outro trabalho maior, que é assisti-lo: há de assistir e insistir sempre com eles, tornando a trabalhar o já trabalhado e a plantar o já plantado e a ensinar o já ensinado, não levantando jamais a mão da obra, porque sempre está por obrar, ainda depois de obrada." (5) 


\section{Solidariedade}

Deixei para o fim a última, mas talvez a mais preciosa lição de Wisner: a solidariedade.

Cheguei à França "sem lenço nem documento". Meu marido era exilado político e eu tinha sido obrigada a viver um ano na clandestinidade no meu país. Recém-formada em Medicina, nunca tinha ouvido falar de Ergonomia. Cheguei ao Laboratório por indicações do professor Philbert, da Faculdade de Medicina, um dos muitos que procurara a partir de indicações de amigos e com o auxílio da lista telefônica. No nosso primeiro encontro, logo após ouvir minha breve história, o professor Wisner me abriu as portas do curso de Ergonomia e me deu todo o apoio de que precisava. E não parou aí. Sempre, durante toda minha estadia em seu país, ele me deu mostras de solidariedade e afeto, nos bons e nos maus momentos por que passei, inclusive me abrindo as portas de sua casa e apresentando-me Jeannine, que se tornou uma grande amiga.

Não fui a única a ser premiada por esta generosidade. Wisner se preocupava com todos os seus alunos e colaboradores e fui testemunha disso nas incontáveis conversas que tive com ele sobre as dificuldades por que passavam uns e outros e que ele prontamente se dispunha a ajudar.

Sem a solidariedade de Wisner, certamente não estaria aqui.

Colocar o trabalho no centro das preocupações, respeitar a inteligência dos povos e exercer a solidariedade: foram essas as principais lições do professor Wisner.

Mais do que lições, elas representam um programa generoso, atual e de longo prazo, que vale a pena ser desenvolvido e continuado.

A situação urge. Nunca se trabalhou tanto no mundo - somos quase 3 bilhões de trabalhadores. E também nunca se sofreu tanto no trabalho, seja pelos seus excessos ou pela sua falta. Os próprios organismos internacionais o reconhecem.

A Organização Internacional do Trabalho - OIT - e a Organização Mundial da Saúde OMS -, em um documento conjunto escrito em fins de 1999 (6), traçaram um quadro extremamente preocupante da situação mundial. Embora admitindo a dificuldade de se fazer estimativas devido à falta de informações confiáveis - na América Latina, por exemplo, parece que "menos que $5 \%$ dos acidentes e doenças do trabalho sejam registradas" (sic) -, os dois organismos apresentam as seguintes estimativas mundiais:

- 250 milhões de acidentes de trabalho a cada ano, levando a 300 mil mortes (o equivalente a mortalidade mundial por malária);

$-1,1$ milhão de mortos por ano em decorrência de doenças ou acidentes do trabalho;

- 160 milhões de novos casos de doenças relacionadas ao trabalho por ano;

- cerca de metade dos trabalhadores em países industrializados sofrendo de stress psicológico por sobrecarga de trabalho;

- acesso restrito a serviços de saúde adequados: apenas $5 \%$ a $10 \%$ dos trabalhadores em países em desenvolvimento e $20 \%$ a $50 \%$ nos países industrializados têm acesso a serviços de saúde adequados. Nos Estados Unidos, por exemplo, 40\% da força de trabalho dos 130 milhões de trabalhadores não têm esse acesso.

O relatório enfatizava que a "globalização" poderia aumentar bastante o número de doenças e acidentes do trabalho no próximo século, pois as pressões pela desregulamentação de padrões básicos de saúde e segurança estão aumentado. Dizia o Dr. Helmer, da OMS: "Para reduzir custos, as indústrias e seus problemas ocupacionais estão sendo transferidos para os países em desenvolvimento, que representam $75 \%$ da força de trabalho global", e onde os salários são mais baixos e os cuidados de saúde e segurança mais precários, quando existem.

O problema está posto. Exige um esforço enorme das nossas inteligências e vontades para ajudar a resolvê-lo. Qual é nosso papel nesta empreitada? Quais são nossas prioridades? Que questões estão a exigir nossos esforços intelectuais para serem, não digo respondidas, mas 
colocadas? Com quem devemos estabelecer alianças para que nossos esforços sejam mais produtivos?

Enfim, o que devemos fazer para seguir as lições do professor Wisner e poder repetir, junto com ele e com orgulho, nous sommes les gens du travail?

\section{Notas}

1- WISNER, A. Ergonomia nos Países em Desenvolvimento. Ação Ergonômica, vol. 1, nº zero, p. 51 (texto da conferência pronunciada no IX Congresso da IEA traduzido do francês e publicado na Ergonomics, 28, 8, 1213-1224 sob o título Ergonomics in Developing Countries).

2- KUORINKA, I. - The IEA Gets Organised: the General Assembly as Governing Body, 1961-1976. Ergonomics International. News and Information, March 2000.

3- Refiro-me a algumas das publicações do Laboratoire dos anos de 1970, publicadas como apostilas, entre elas: Conditions de travail des femmes O.S. dans la construction électronique, de A. Laville, E. Richard e A. Wisner; Conséquences du travail répétitif sous cadence sur la santé des travailleurs et les accidents, de A. Laville e J. Duraffourg, de 1972; Tâches répétitives sous contrainte de temps et charge de travail - étude des conditions de travail dans un atelier de confection, de C. Teiger, A. Laville e J. Duraffourg, 1973; Renseignements téléphoniques avec lecture de microfiches sous contrainte temporelle. Analyse des exigences du travail et de leurs conséquences physiologiques, psychologiques et sociales, de C. Teiger, A. Laville, D. Dessors e C. Gadbois, de 1977; Etude comparative d'ouvriers de 40 à 45 ans travaillant dans deux ateliers de l'industrie automobile, de J. Marcelin e M. Valentin.

4- Citado por Wisner em Quando voyagent les usines, essai de anthropotecnologie. Paris: Syros Collection, Atelier Futur, 1985.

5- VIEIRA, A. Sermão do Espírito Santo, pronunciado em 1657 na lgreja da Companhia de Jesus, em São Luís do Maranhão. Sermões, Tomo I, Alcir Pécora (org.). São Paulo: Hedra, 2000.

6- Ver especialmente o Communiqué de Presse OMS/31 de 8/6/99, intitulado La charge des maladies professionnelles: mise en garde de l'OMS et de l'OIT (www.who.int/inf-pr-1999/fr/cp9931.html) e o documento, também da OMS, Occupational Health, Ethically Correct, Economically Sound, nos Fact Sheet $\mathrm{n}^{\circ}$ 84, revised June 1999 (www.who.int/inffs/en/fact084.html). 